\title{
Naturalistic Outcome of Family-Based Inpatient Treatment for Adolescents with
}

\section{Anorexia Nervosa}

\author{
Inger Halvorsen, M.D., Ph.D. ${ }^{1}$, Deborah Lynn Reas, PhD ${ }^{1,2}$, \\ Jan-Vegard Nilsen, Cand.psych. ${ }^{1}$, and Øyvind Rø, M.D., Ph.D. ${ }^{1,3}$
}

${ }^{1}$ Regional Department for Eating Disorders, Division of Mental Health and Addiction, Oslo University Hospital, Norway

${ }^{2}$ Department of Psychology, Faculty of Social Sciences, University of Oslo, Norway

${ }^{3}$ Division of Mental Health and Addiction, Institute of Clinical Medicine, University of Oslo, Norway

\section{Corresponding author:}

Inger Halvorsen, Regional Department for Eating Disorders, Division of Mental Health and Addiction, Oslo University Hospital - Ullevål Hospital, P.O. Box 4956 Nydalen, N0424 Oslo, Norway

Tel.: +47 91550073/ +47 23016230; Fax: +47 23016231

e-mail: inger.halvorsen@uus.no

Financial Support: This study was internally funded by the Regional Department for Eating Disorders, Oslo University Hospital, Norway.

Running Head: FAMILY-BASED INPATIENT TREATMENT FOR ADOLESCENT AN 


\begin{abstract}
Background: Outpatient family-based treatment (FBT) is the best-documented treatment for adolescent anorexia nervosa (AN), but research is scarce on FBT adapted to inpatient settings.
\end{abstract} Aims: To investigate the naturalistic outcome of inpatient FBT for adolescent AN.

Methods: Thirty-seven (65\%) of 57 patients who received inpatient FBT at a tertiary adolescent eating disorders (ED) unit participated in a follow-up interview (mean $4.5 \pm 1.8$, range 1-7 yrs) that assessed ED symptoms and general psychological functioning.

Results: A majority (65\%) had achieved a normal body weight (BMI $\geq 18.5)$. Thirty-six percent $(n=12)$ were classified as fully recovered, as defined by BMI $\geq 18.5$, EDE-Q global $\leq 2.5$, and no binge eating/purging over past 3 months. Sixteen (43\%) participants met criteria for one or more additional comorbid disorders.

Conclusion: Inpatient family-based therapy for AN may be a promising therapeutic approach for adolescents that fail to respond to outpatient treatment, and should be investigated further.

Key words: Family-Based Therapy, Anorexia Nervosa, Eating Disorders, Adolescent, Inpatient Treatment 


\section{Introduction}

Although family-based treatment (FBT) is the best documented intervention for adolescent AN (Couturier, Kimber, \& Szatmari, 2013; Lock, 2015; NICE, 2017), a substantial proportion (10-66\%) of patients fail to achieve remission (Couturier et al., 2013). FBT was originally designed for delivery on an outpatient basis, and in the event of hospitalization, the initiation of FBT is typically delayed until after discharge (Lock \& le Grange, 2012). However, a significant proportion of young people with AN fail to show rapid and lasting improvement, which entails massive costs for the young person's health and development, as well as for the family and society. A few recent studies have described adapting and incorporating FBT principles into intensive outpatient or partial hospitalization programs for adolescents with eating disorders (Hoste, 2015; Murray et al., 2015). The application of FBT principles into these different levels of care has been associated with improved outcomes (Girz, Robinson, Foroughe, Jasper, \& Boachie, 2013; Henderson et al., 2014; Ornstein, Lane-Loney, \& Hollenbeak, 2012).

A significant proportion of adolescents with AN require inpatient hospitalization due to unstable or life-threatening physical conditions related to starvation and/or persistent low weight inadequately addressed by lower levels of care. In these cases, inpatient treatment is shown beneficial for weight gain, although hospitalization may be less effective in improving other ED and mood symptoms (Goddard et al., 2013). When inpatient management for children and adolescents with AN is required, it is particularly important to involve parents and carers in the treatment (NICE, 2017). If parents are not closely engaged in the daily care and treatment during the hospital stay, treatment may fail to strengthen their confidence in their own ability to help their child and to manage meals at home, which are crucial elements in FBT. Thus, it may be important to apply treatment principles from outpatient FBT to 
inpatient settings for adolescents with AN. However, research on outcome, efficacy and feasibility of family-based inpatient treatment is so far lacking, and, to our knowledge, no previous study has reported results of inpatient FBT for adolescent AN. The aim of this study was to investigate the naturalistic outcome of inpatient FBT at a tertiary ED unit for adolescents in terms of weight, ED symptoms, comorbid disorders and treatment received during the follow-up period. 


\section{Methods}

\section{Participants}

The Regional Department for Eating Disorders at Oslo University Hospital provides highlyspecialized services for a catchment area of 2.8 million inhabitants in Southern and Eastern Norway. Patients are referred from specialized mental health services and have received previous inpatient and outpatient treatment, including family-based interventions, at their local hospitals without success. The adolescent inpatient unit has a maximum of five beds for patients to be admitted with their families. The unit changed the standard treatment program offered from individual-based to family-based treatment in May, 2008. This decision was based upon evidence supporting the effectiveness of FBT for adolescent AN in outpatient settings. Patients under 18 years old in Norway have the right to be accompanied by a parent during hospital stays, and parents receive financial benefits during the hospitalization.

All former patients $(n=57)$ who had received inpatient FBT for AN during the period May 2008 - June 2014 were successfully contacted. Sixty five per cent (33 females and 4 males) consented to participate in the study. There were no significant differences between the 37 participants and 20 non-participants on demographic or clinical variables during the admission. Only one patient dropped out from treatment (a non-participant). In case of any readmissions to the unit, the focus of the follow-up visit was based on the initial family admission. Among the 37 participants, admission was based on parental consent for patients under 16 years $(n=19)$, while $14(78 \%)$ of patients over 16 years were treated voluntarily and four $(22 \%)$ compulsory. For baseline characteristics, see Table 1.

\section{Treatment}


All families agreed to stay at the hospital with their child during treatment. Siblings were also welcome, but in most cases they remained at home during the majority of the admission. Typically, both of the parents stayed at the unit during the first phase of the treatment, and thereafter alternated between staying at the hospital versus at home with siblings. If the parents did not live together $(\mathrm{N}=12,32 \%)$, the parents took turns staying at the hospital, while both participated in treatment meetings, parental counseling, and family sessions. Only one of the parents was available to participate in treatment for eight of the families, typically due to health problems affecting the other parent, or due to sole custody.

Treatment principles from the Maudsley FBT (Lock \& le Grange, 2012) were adapted and modified for delivery on an inpatient setting. Treatment was designed to help parents establish clear, predictable frameworks for meals with adequate amounts of food at the hospital and at home. The family ate all meals together in a designated family room or a designated table in the main dining room, receiving support from the staff as needed. Milieu therapy staff aimed to support the whole family in coping with the ED, reducing conflicts, and promoting cooperation and positive relationships between family members. A weekly weight gain of approximately $1 \mathrm{~kg}$ was recommended. The family reviewed daily progress with the staff, attended joint family sessions once or twice a week, parental counseling and weekly group sessions for parents. Most patients were also offered weekly individual sessions. Weekend leaves were integrated into treatment to encourage families to practice and transfer skills to the home environment, with longer leaves granted toward the end of hospitalization.

\section{Assessment at follow-up:}

Semi-structured interviews and questionnaires assessed socio-demographic variables, eating disorder symptomology, ED-related impairment, comorbid symptomology, as well as 
treatment received during the follow-up phase. The interviews were audiotaped and conducted by the first author (IH) and two staff clinical psychologists.

\section{Instruments and measures}

The diagnostic items of the Eating Disorder Examination 16.0 (EDE; Fairburn, Cooper, \& O'Connor, 2008) were used to assess whether participants fulfilled ED diagnostic criteria (APA, 2013).

The Eating Disorder Examination Questionnaire 6.0 (EDE-Q; Fairburn \& Beglin, 1994) assessed core ED symptoms and behaviors during the previous 28 days. An EDE-Q global score $\leq 2.5$ has been demonstrated as the clinical threshold to optimally distinguish caseness in a sample of Norwegian women (Ro, Reas, \& Stedal, 2015).

The Clinical Impairment Assessment (CIA; Bohn et al., 2008) is a brief self-report measure to assess psychosocial impairment due to ED features over the past 28 days. A clinical threshold of 16.0 has been consistently found to optimally distinguish caseness based on ED-related impairment (Bohn et al., 2008; Reas, Stedal, Lindvall-Dahlgren, \& Rø, 2016).

The Mini International Neuropsychiatric Interview version 6.0 (MINI; Sheehan et al., 1998) was used to assess other mental disorders.

The Beck Depression Inventory (BDI; Beck, Steer, \& Carbin, 1988) measures symptoms of depression.

The State and Trait Anxiety Inventory (STAI; Bieling, Antony, \& Swinson, 1998) measures anxiety on two dimensions: state (how you feel just now) and trait (how you feel in general).

\section{Body weight and height}

Body mass index (BMI, $\left.\mathrm{kg} / \mathrm{m}^{2}\right)$ at follow-up was calculated from either measured $(\mathrm{n}=16)$ or self-reported weight BMI percentiles for age and sex were calculated using a Norwegian 
version of a weight-for-height ratio calculator based on reference data from Child Growth Foundation, United Kingdom (Cole, Freeman, \& Preece, 1995).

\section{Outcome criteria}

Weight recovered: Normal body weight at follow-up was defined as $B M I \geq 18.5$.

Fully recovered: Normalized eating attitudes and behavior was defined as an EDE-Q global score $\leq 2.5$, no episodes of binge eating or purging/other compensatory behavior during the last three months, and $\mathrm{BMI} \geq 18.5$.

\section{Statistical analyses}

Independent and paired t-tests were used to investigate differences between and within participants. All analyses were two-tailed. The alpha level was set at $\mathrm{p} \leq .05$.

The study was approved by the Regional Medical Ethics Committee. 


\section{Results}

Characteristics at follow-up are shown in Table 1. The average length of hospital stay was $20.6 \pm 13.6$ weeks, including temporary leaves from hospital. The average time between discharge and follow-up was $4.5 \pm 1.8$ years (range: $1.3-7.1$ ). Mean body weight improved during the admission $(7.6 \pm 4.3 \mathrm{~kg})$ and the mean BMI percentile at discharge $(21.4 \pm 17.8)$ was in the normal range (i.e., $>12$, which corresponds to approximately BMI 18.5 in adults).

At follow-up, there was no mortality. A total of $65 \%$ of the participants had achieved a normal body weight $(\mathrm{BMI} \geq 18.5)$ and were classified as "weight-recovered." Of the 33 participants with complete EDE-Q data, 19 (58\%) had an EDE-Q global score in the normal range $(\leq 2.5)$, as well as no binge eating or purging/other compensatory behavior during the past three months. A total of $36 \%$ were classified as "fully recovered" (i.e., BMI $\geq 18.5$, EDEQ global score $\leq 2.5$, and no binge eating/purging past 3 months). For the total group, the mean EDE-Q global score was $2.2( \pm 1.5)$ and the mean CIA was $15.9( \pm 11.7)$. According to the diagnostic items of the EDE interview, 59\% percent no longer met full criteria for any ED at follow-up, $22 \%$ met criteria for AN, $5 \%$ for BN, and $14 \%$ for unspecified ED. Forty-three percent $(n=16)$ had one or more comorbid psychiatric diagnoses (see Table 1). All except four participants had received further ED treatment following discharge, and 14 (38\%) of the participants had been re-hospitalized, including seven cases with more than one readmission.

Twenty-five (68\%) participants were students, seven were employed (4 in skilled work, 3 in unskilled work), and five reported no current work or studies due to health problems. Over the last four weeks, 19 (51\%) participants were working or studying full time, and nine (24\%) part-time (more than $50 \%$ work or studies). 


\section{Discussion}

This study reports outcome from an inpatient family-based treatment program for adolescent AN. At a mean follow-up of 4.5 years (range: $1-7$ years), $65 \%$ were classified as "weight recovered" (BMI $\geq 18.5)$. A total of $36 \%$ were classified "fully recovered", as defined by a $\mathrm{BMI} \geq 18.5$, global EDE score within the normal range, and no binge/purge behavior during the past three months. The majority of the former patients (59\%) no longer met full DSM-5 diagnostic criteria for any ED.

Prior studies investigating the effectiveness of FBT for adolescents with AN have utilized outpatient samples. The proportion of patients achieving a good outcome in outpatient FBT trials varies greatly across studies, with end-of-treatment remission (i.e., $\geq 85 \%$ of ideal body weight (IBW)) ranging widely between 34\% and 90\%, and 6-12 month follow-up remission rates ranging between 29\% and 79\% (Couturier et al., 2013). However, one study that applied a stricter definition of recovery (i.e., $\geq 95 \%$ of IBW and a global EDE score within the normal range), found a remission rate of only $34 \%$ at end-of-treatment and $36 \%$ at one-year follow-up (Lock et al., 2010). Our remission rate is comparatively similar, or better than, some of the FBT studies conducted on an outpatient basis. This is despite the present sample constituting a severely ill group treated at a tertiary inpatient service, and characterized by a prior history of failed treatment. However, several of the prior FBT studies had a shorter duration of followup (i.e., 6-12 months) than ours, and there is some evidence that longer follow-ups are associated with better outcome (Keel \& Brown, 2010).

We found that nearly half (43\%) of former patients had a comorbid, non-ED psychiatric diagnosis at follow-up, which is in accordance with prior studies (Halvorsen et al., 2004; Herpertz-Dahlmann, 2015). Anxiety disorders were the most prevalent diagnoses, affecting $38 \%$ of the participants. These findings underscore that comorbidity, and particularly anxiety 
disorders, warrant specific clinical attention in adolescents with AN. However, despite the high prevalence of comorbid diagnoses, the majority had successfully finished an ageappropriate level of education and was engaged in full-time or part-time work or studies.

In considering the overall benefits versus costs of family-based hospital admissions for adolescent $\mathrm{AN}$, there are several reasons that family admissions may prove beneficial for cases in which lower levels of care have proven inadequate. First, family admissions allow parents to provide uninterrupted care and support for their severely ill child throughout the hospitalization. Individual admissions may entail negative effects related to separation from primary caregivers during severe illness, and be less effective in building parents' skills and confidence in illness management. Moreover, increased feelings of efficacy and acquisition of skills to successfully cope and manage the ED may reduce parental distress and improve caregiver mental health (Girz et al., 2013). Severe AN during adolescence is enormously demanding on all families, and the resources required to provide care for adolescents with AN, in addition to parents' own high distress levels, may lead to impairment in their social and occupational functioning even when individual admissions are used. Various perspectives on whether family admissions are more expensive than individual admissions hinges on a short-versus-long-term view of outcome for the patient and stakeholders, including hospitalization utilization, staff requirements, parental leave of absence from employment, and potential negative or iatrogenic effects of hospitalization (Lock et al., 2008).

To our knowledge, this is the first study to report outcome for family-based treatment for adolescent AN delivered on an inpatient basis. This study represents a novel contribution to the literature by extending prior research on outpatient FBT. Established self-report assessment and structured interviews were administrated. There was very low drop-out from 
treatment (1/57), all families were successfully contacted, and $65 \%$ of former patients were interviewed. Although the follow-up time was variable (1.3 - 7.1 years), the average followup duration was lengthy compared to most other AN outcome studies.

However, this study has several limitations which should be noted. The sample size was small, and, thus, the power to detect differences between subgroups was low. Due to the naturalistic study design, we cannot conclude that outcome was directly related to the family admission. Almost all participants had received some additional treatment following discharge. We relied upon self-reported weight and height at follow-up in several cases, and two of the interviewers had formerly been therapists working on the adolescent unit. In Norway, patients under 18 years old have the right to be accompanied by a parent during hospital stays, and parents receive financial benefits during the hospitalization. This is a generous law that enables parents to participate extensively in treatment, and our findings may therefore not be generalizable to other healthcare systems.

In conclusion, our findings suggest that inpatient family-based therapy for adolescent AN may be a promising therapeutic approach for adolescents that fail to respond to adequate outpatient treatment. Further research is warranted to investigate the efficacy and feasibility of adapting and delivering FBT during hospitalization for AN. 


\section{References}

APA. (2013). Diagnostic and Statistical Manual of Mental Disorders (5 th edn.). Washington DC: American Psychiatric Association.

Beck, A. T., Steer, R.A., Garbin, M.G. (1988). Psychometric properties of the Beck Depression Inventory: Twenty-five years of evaluation. Clinical Psychology Review, 8, 23. DOI:10.1016/0272-7358(88)90050-5

Bieling, P. J., Antony, M. M., \& Swinson, R. P. (1998). The State-Trait Anxiety Inventory, Trait version: structure and content re-examined. Behav Res Ther, 36(7-8), 777-788. DOI:10.1016/S0005-7967(98)00023-0

Bohn, K., Doll, H. A., Cooper, Z., O'Connor, M., Palmer, R. L., \& Fairburn, C. G. (2008). The measurement of impairment due to eating disorder psychopathology. Behav.Res.Ther., 46(10), 1105-1110. DOI:10.1016/j.brat.2008.06.012

Cole, T. J., Freeman, J. V., \& Preece, M. A. (1995). Body mass index reference curves for the UK, 1990. Arch.Dis.Child., 73(1), 25-29.

Couturier, J., Kimber, M., \& Szatmari, P. (2013). Efficacy of family-based treatment for adolescents with eating disorders: a systematic review and meta-analysis. Int.J.Eat.Disord., 46(1), 3-11. DOI: $10.1002 /$ eat.22042

Eisler, I., Simic, M., Russell, G. F., \& Dare, C. (2007). A randomised controlled treatment trial of two forms of family therapy in adolescent anorexia nervosa: a five-year follow-up. J.Child Psychol.Psychiatry, 48(6), 552-560. DOI:10.1111/j.1469-7610.2007.01726.x

Fairburn, C. G., \& Beglin, S. J. (1994). Assessment of eating disorders: interview or self-report questionnaire? Int.J.Eat.Disord., 16(4), 363-370. DOI:10.1002/1098108X(199412)16:4<363::AID-EAT2260160405>3.0.CO;2-\#

Fairburn, C. G., Cooper, Z., \& O'Connor, M. (2008). The Eating Disorder Examination (16.0D). In C. G. Fairburn (Ed.), Cognitive Behavior Therapy and Eating Disorders. New York: Guilford Press.

Girz, L., Lafrance Robinson, A., Foroughe, M., Jasper, K., \& Boachie, A. (2013). Adapting familybased therapy to a day hospital programme for adolescents with eating disorders: preliminary 
outcomes and trajectories of change. Journal of Family Therapy, 35, 102-120.

DOI:10.1111/j.1467-6427.2012.00618.x

Goddard, E., Hibbs, R., Raenker, S., Salerno, L., Arcelus, J., Boughton, N., . . Treasure, J. (2013). A multi-centre cohort study of short term outcomes of hospital treatment for anorexia nervosa in the UK. BMC.Psychiatry., 13:287. DOI: 10.1186/1471-244X-13-287., 287-213.

Halvorsen, I., Andersen, A., \& Heyerdahl, S. (2004). Good outcome of adolescent-onset anorexia nervosa after systematic treatment. Intermediate to long-term follow-up of a representative county-sample. Eur.Child Adolesc.Psychiatry, 13, 295-306. DOI:10.1007/s00787-004-0408-9

Henderson, K., Buchholz, A., Obeid, N., Mossiere, A., Maras, D., Norris, M., . . Spettigue, W. (2014). A Family-Based Eating Disorder Day Treatment Program for Youth: Examining the Clinical and Statistical Significance of Short-Term Treatment Outcomes. Eating Disorders, 22(1), 1-18. DOI:10.1080/10640266.2014.857512

Herpertz-Dahlmann, B. (2015). Adolescent eating disorders: update on definitions, symptomatology, epidemiology, and comorbidity. Child Adolesc Psychiatr Clin N Am, 24(1), 177-196. DOI: 10.1016/j.chc.2014.08.003

Hoste, R. R. (2015). Incorporating family-based therapy principles into a partial hospitalization programme for adolescents with anorexia nervosa: challenges and considerations. Journal of Family Therapy, 37(1), 41-60. DOI:10.1111/1467-6427.12055

Keel, P. K., \& Brown, T. A. (2010). Update on course and outcome in eating disorders. Int.J.Eat.Disord. DOI:10.1002/eat.20810

Lock, J. (2015). An Update on Evidence-Based Psychosocial Treatments for Eating Disorders in Children and Adolescents. J.Clin.Child Adolesc.Psychol., 44(5), 707-721. DOI:10.1080/15374416.2014.971458

Lock, J., Couturier, J., \& Agras, W. S. (2008). Costs of remission and recovery using family therapy for adolescent anorexia nervosa: a descriptive report. Eat.Disord., 16(4), 322-330. DOI:10.1080/10640260802115969

Lock, J., le Grange, D., Agras, W. S., Moye, A., Bryson, S. W., \& Jo, B. (2010). Randomized clinical trial comparing family-based treatment with adolescent-focused individual therapy for 
adolescents with anorexia nervosa. Arch.Gen.Psychiatry., 67(10), 1025-1032.

DOI:10.1001/archgenpsychiatry.2010.128

Lock, J., le Grange, D. (2012). Treatment Manual for Anorexia Nervosa. A Family-Based Approach. 2nd edition. New York: Guilford Press.

Murray, S. B., Anderson, L. K., Rockwell, R., Griffiths, S., le, G. D., \& Kaye, W. H. (2015). Adapting Family-Based Treatment for Adolescent Anorexia Nervosa Across Higher Levels of Patient Care. Eat.Disord., 23(4), 302-314. DOI:10.1080/10640266.2015.1042317

NICE. (2017). Eating disorders: recognition and treatment. NICE guideline NG69. London.

Ornstein, R. M., Lane-Loney, S. E., \& Hollenbeak, C. S. (2012). Clinical outcomes of a novel, familycentered partial hospitalization program for young patients with eating disorders. Eat.Weight.Disord., 17(3), e170-e177.

Reas, D. L., Stedal, K., Lindvall Dahlgren, C., \& Ro, O. (2016). Impairment due to eating disorder pathology: Identifying the cut-off score on the Clinical Impairment Assessment in a clinical and community sample. Int J Eat Disord, 49(6), 635-638. DOI:10.1002/eat.22517Ro, O., Reas, D. L., \& Stedal, K. (2015). Eating Disorder Examination Questionnaire (EDE-Q) in Norwegian Adults: Discrimination between Female Controls and Eating Disorder Patients. Eur Eat Disord Rev, 23(5), 408-412. DOI: 10.1002/erv.2372

Sheehan, D. V., Lecrubier, Y., Sheehan, K. H., Amorim, P., Janavs, J., Weiller, E., . . Dunbar, G. C. (1998). The Mini-International Neuropsychiatric Interview (M.I.N.I.): the development and validation of a structured diagnostic psychiatric interview for DSM-IV and ICD-10. 2. J.Clin. Psychiatry, 59 Suppl 20, 22-33. 
Table 1 Baseline and follow-up characteristics of the sample $(n=37)$

\begin{tabular}{|c|c|c|c|c|}
\hline & \multicolumn{2}{|c|}{ At admission } & \multicolumn{2}{|c|}{ At follow-up } \\
\hline & Mean \pm SD & Range & Mean \pm SD & Range \\
\hline Age at onset (yrs) & $13.2 \pm 1.9$ & $7-17$ & & \\
\hline Age at admission/follow-up (yrs) & $15.7 \pm 1.9$ & $12.4-19.5$ & $20.2 \pm 2.6$ & $15.8-25.3$ \\
\hline Duration of admission (weeks) & $20.6 \pm 13.6$ & $3-58$ & & \\
\hline Follow-up time (years) & & & $4.5 \pm 1.8$ & $1.3-7.1$ \\
\hline Body weight $(\mathrm{kg})$ at admission / follow-up & $42.3 \pm 5.4$ & $29.7-55.7$ & $56.1 \pm 10.4$ & $42.5-103.0$ \\
\hline BMI at admission / follow-up & $15.4 \pm 1.4$ & $13.2-19.3^{1}$ & $19.9 \pm 3.0$ & $15.6-30.8$ \\
\hline BMI percentile at admission / follow-up & $3.1 \pm 6.1$ & $<0.1-35.6$ & $27.0 \pm 29.6$ & $<0.1-98.2$ \\
\hline Weight gain $(\mathrm{kg})$ during admission & $7.5 \pm 4.4$ & $-1.1-14.8$ & & \\
\hline Weight gain $(\mathrm{kg})$ from discharge to follow-up & & & $6.3 \pm 9.4$ & $-7.3-42.5$ \\
\hline DSM-5 ED diagnoses & $\mathbf{N}$ & $\%$ & $\mathbf{N}$ & $\%$ \\
\hline No ED diagnosis & 0 & 0 & 22 & 59 \\
\hline Anorexia Nervosa $^{2}$ & 37 & 100 & 8 & 22 \\
\hline Bulimia Nervosa & 0 & 0 & 2 & 5 \\
\hline Other specified or unspecified feeding or eating disorder & 0 & 0 & 5 & 14 \\
\hline \multicolumn{5}{|l|}{ Other psychiatric diagnoses: } \\
\hline At least one diagnosis & & & 16 & 43 \\
\hline Anxiety disorder ${ }^{3}$ & & & 14 & 38 \\
\hline Depressive disorder $^{4}$ & & & 8 & 22 \\
\hline Questionnaire results at follow-up $^{5}$ & & & Mean \pm SD & \\
\hline EDE-Q $^{6}$ global & & & $2.2 \pm 1.5$ & \\
\hline Clinical Impairment Assessment & & & $15.9 \pm 11.7$ & \\
\hline State and Trait Anxiety Inventory: State & & & $45.9 \pm 14.3$ & \\
\hline State and Trait Anxiety Inventory: Trait & & & $51.6 \pm 10.4$ & \\
\hline Beck Depression Inventory & & & $17.9 \pm 12.2$ & \\
\hline $\begin{array}{l}{ }^{1} \text { One patient with AN diagnosis at admission had BMI }>18.5 \text {. She was tr } \\
\text { underweight, and was unable to maintain a normal body weight outside } \\
\text { restricting type and } n=1 \text { binge/purge type; AN subtypes at follow-up: } n \\
\text { those diagnosed with anxiety disorder, } n=6 \text { had one anxiety disorder an } \\
\text { were as follows: panic disorder }(n=5) \text {, agoraphobia }(n=5) \text {, social phobia } \\
n=16 \text { other participants had lifetime depressive disorder. }{ }^{5} 33 \text { participan } \\
\text { Questionnaire. }\end{array}$ & $\begin{array}{l}\text { d from local in } \\
\text { 1. }{ }^{2} \text { AN subtype } \\
\text { diagnosed witl } \\
\text { d two or more } \\
\text { generalized anx } \\
\text { omplete questic }\end{array}$ & $\begin{array}{l}\text { atient treatment, } \\
\text { at admission: } n= \\
\text { restricting and } n= \\
\text { nxiety disorders. } \\
\text { ety disorder }(n=9) \\
\text { naire data. }{ }^{5} \text { Eatin }\end{array}$ & $\begin{array}{l}\text { we she had been } \\
\text { were diagnosed } \mathrm{w} \\
\text { inge/purge type. } \\
\text { cific anxiety diso } \\
\text { d OCD }(\mathrm{n}=3) .{ }^{4} \mathrm{~A} \\
\text { isorder Examina }\end{array}$ & $\begin{array}{l}\text { verely } \\
\text { h } \\
\text { Of } \\
\text { lers } \\
\text { o, } \\
\text { on- }\end{array}$ \\
\hline
\end{tabular}


